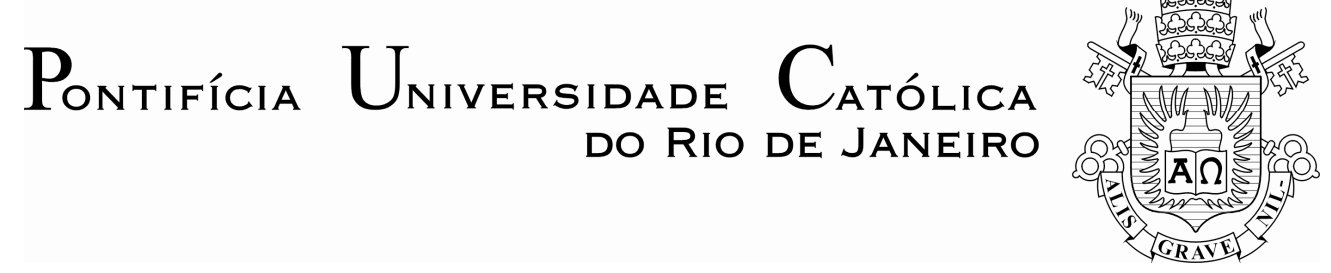

Fabiano Correia Santério

Controle baseado em comportamentos de robôs móveis autônomos com sensores ópticos e ultrassônicos

\begin{abstract}
Dissertação de Mestrado
Dissertação apresentada como requisito parcial para obtenção do título de Mestre pelo Programa de Pós-Graduação em Engenharia Mecânica da PUC-Rio.
\end{abstract}

Orientador: Prof. Marco Antonio Meggiolaro 


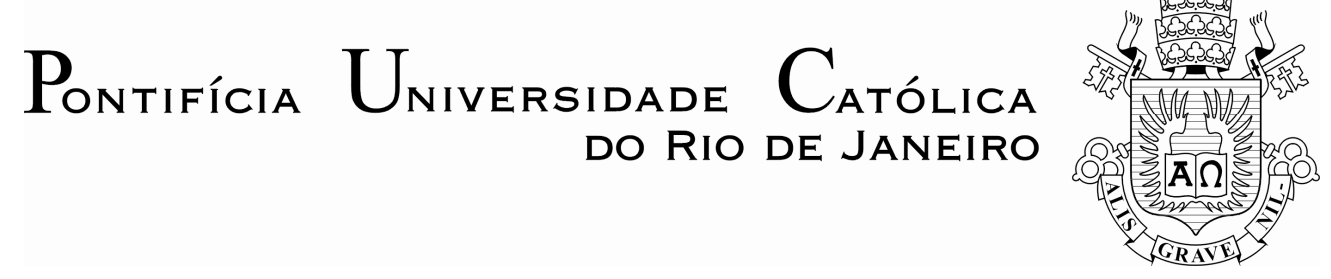

Fabiano Correia Santério

\section{Controle baseado em comportamentos de robôs móveis autônomos com sensores ópticos e ultrassônicos}

Dissertação apresentada como requisito parcial para obtenção do título de Mestre pelo Programa de PósGraduação em Engenharia Mecânica da PUC-Rio. Aprovada pela Comissão Examinadora abaixo assinada.

\section{Prof. Marco Antonio Meggiolaro}

Orientador

Departamento de Engenharia Mecânica - PUC-Rio

Prof. Mauro Speranza Neto

Departamento de Engenharia Mecânica - PUC-Rio

Prof. Armando Morado Ferreira Instituto Militar de Engenharia - IME

Prof. José Eugênio Leal Coordenador(a) Setorial do Centro Técnico Científico - PUC-Rio 
Todos os direitos reservados. É proibida a reprodução total ou parcial do trabalho sem autorização da universidade, do autor e do orientador.

\section{Fabiano Correia Santério}

Graduou-se em Engenharia de Controle e Automação (Pontifícia Universidade Católica) em 2005. Trabalha a quatro anos na área de automação predial e naval nos setores de projeto, implementação e controle de sistemas. Iniciou o mestrado na área de Mecânica Aplicada na PósGraduação da PUC-Rio em 2007. Suas áreas de interesse abrangem projeto, implementação e controle processos de automação industrial, naval e predial assim como na área da robótica voltada para indústria offshore.

Ficha Catalográfica

\section{Santério, Fabiano Correia}

Controle baseado em comportamentos de robôs móveis autônomos com sensores ópticos e ultrassônicos / Fabiano Correia Santério ; orientador: Marco Antonio Meggiolaro. - 2010.

140 f. : il. (color.) ; $30 \mathrm{~cm}$

Dissertação (Mestrado em Engenharia Mecânica)-Pontifícia Universidade Católica do Rio de Janeiro, Rio de Janeiro, 2010.

Inclui bibliografia

1. Engenharia mecânica - Teses. 2. Robô móvel. 3. Robô autônomo. 4. Controle baseado em comportamentos. 5. Sensores ópticos. 6. Sensores ultrassônicos. I. Meggiolaro, Marco Antonio. II. Pontifícia Universidade Católica do Rio de Janeiro. Departamento de Engenharia Mecânica. III. Título. 


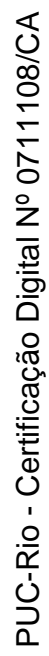

aos meus pais, Edison e Laura. 


\title{
Agradecimentos
}

\author{
À Deus.
}

À Vice-Reitoria Acadêmica (CCPG), pelo apoio financeiro;

À PUC-Rio pelo seu excelente corpo docente e infra-estrutura que possibilitou toda minha plataforma de estudos;

Ao orientador Marco Antonio Meggiolaro, pela dedicação, ensinamentos, orientação e incentivos que me fizeram alcançar meus objetivos;

Ao professor Mauro Speranza Neto, pelo apoio e orientação que me guiaram e incentivaram desde a época da graduação;

A meu pai e minha mãe, que sempre me deixaram livre nas escolhas de meu futuro e ao mesmo tempo apoiaram e incentivaram todas minhas decisões acadêmicas e profissionais baseados na ética e valores morais que me passaram;

Aos alunos de graduação e pós-graduação que frequentaram o laboratório de controle e automação durante todo meu mestrado, que me ajudaram muito para a conclusão desse trabalho; 


\section{Resumo}

Santério, Fabiano C., Meggiolaro, Marco A. Controle baseado em comportamentos de robôs móveis autônomos com sensores ópticos e ultrassônicos. Rio de Janeiro 2010. 140p. Dissertação de Mestrado Departamento de Engenharia Mecânica, Pontifícia Universidade Católica do Rio de Janeiro.

O comportamento animal serviu de inspiração para o controle baseado por comportamento aplicado a robôs móveis autônomos. Este se baseia em diretivas simples, ou reações, separadas por camadas com respectivas prioridades. Quando agrupadas, estas diretivas conseguem executar as mais diversas e complexas funções no ambiente, tornando o controle em si uma tarefa segmentada, na qual se divide o objetivo principal em pequenos módulos chamados de comportamentos primários. Estes atuam independentes e, ao trabalharem de forma paralela resultam em comportamentos complexos capazes de realizar tarefas mais complexas, uma evolução do controle reativo. A lógica desta técnica torna mais simples a programação e organização das tarefas porque possui uma estrutura modular que permite a adição de novos sensores (novos comportamentos), sem grandes mudanças no código existente. Esta dissertação desenvolve e implementa a programação baseada em comportamento em robôs móveis autônomos com sensores óticos e ultrassônicos em um ambiente de simulação open source muito comum chamado Player/Stage e validada experimentalmente em 2 robôs autônomos. A arquitetura utilizada no processo de desenvolvimento das camadas comportamentais foi a arquitetura de esquemas motores em conjunto com a técnica de campos potenciais, originalmente idealizada por Ronald C. Arkin em 1998. Os resultados simulados e experimentais foram confrontados com métodos de programação clássica e comprovam todas as vantagens do controle baseado em comportamento.

\section{Palavras-chave}

Robô móvel; robô autônomo; controle baseado em comportamentos; sensores ópticos; sensores ultrassônicos. 


\section{Abstract}

Santério, Fabiano C., Meggiolaro, Marco A. (Advisor) Behavior based control of autonomous robots with optical and ultrasonic sensors. Rio de Janeiro 2010. 140p. MSc Dissertation - Departamento de Engenharia Mecânica, Pontifícia Universidade Católica do Rio de Janeiro.

The animal behavior served as the inspiration for the behavior based control applied to autonomous mobile robots. This is based on simple directives, or reactions, separated by layers with their priorities. When combined, these directives can run the most diverse and complex functions in the environment, making the control itself a segmented task, which divides the main objective into small modules called primary behaviors. Those act independently and, when working in parallel, result in complex behaviors that are capable of executing more complex tasks, an evolution of reactive control. The logic from this technique makes it easy to program and organize robot controllers because it has a modular structure that allows the addition of new sensors (new behaviors) without major changes in the existing code. This thesis develops and implements a behavior based programming on autonomous mobile robots with optical and ultrasonic sensors in very common open source simulation software, called Player/Stage, and validates experimentally in 2 autonomous robots. The architecture used in the development of behavioral layers was the motor schema with potential fields, originally created by Ronald C. Arkin in 1998. The simulated and experimental results were confronted with classical methods of programming and proved all the benefits of behavior based control.

\section{Keywords}

Mobile robot; autonomous robot; behavior based control; optical sensors; ultrasonic sensors. 


\section{Sumário}

1. Introdução 13

1.1. Origens 13

1.2. Motivação 14

1.3. Objetivo e Contribuição 19

1.4. Organização da Dissertação 20

2. Embasamento Teórico 21

2.1. Robôs Móveis Autônomos 21

2.2. Sistemas de Controle 24

2.3. Técnicas de Controle 25

2.4. Arquiteturas de Controle 25

2.4.1. Arquitetura Horizontal 26

2.4.2. Arquitetura Vertical 27

2.4.3. Arquitetura Híbrida 29

2.5. Estratégias de Controle $\quad 30$

2.5.1. Controle Deliberativo 30

2.5.2. Controle Reativo 31

2.5.3. Controle Híbrido - Reativo/Deliberativo 34

2.5.4. Controle Baseado em Comportamento 35

2.6. Ambiente de Simulação Player / Stage 51

3. Sensoriamento 55

3.1. Sensoriamento da Simulação 55

3.2. Sensoriamento do Experimento 60

4. Simulações 63

4.1. Simulação Completa 63

4.2. Comparativo Clássico X Comportamento 76

4.2.1. Controle Baseado em Comportamento 76

4.2.2. Controle Clássico de Trajetórias 79 
4.2.3. Comparação

5. Validação Experimental 93

5.1. Robôs 93

5.2. Predador / Presa 96

6. Conclusões 105

$\begin{array}{ll}\text { Referências Bibliográficas } & 107\end{array}$

$\begin{array}{ll}\text { Apêndice I } & 112\end{array}$

$\begin{array}{ll}\text { Apêndice II } & 114\end{array}$

$\begin{array}{ll}\text { Apêndice III } & 129\end{array}$ 


\section{Lista de figuras}

Figura 1 - Robôs interplanetários SRR (Sample Return Rover) e FIDO

(Field Integrated Design and Operations). (SCHENKER, 2003) [14]

Figura 2 - Controle Reativo em robô com funções de escritório.

(FENG, 1994) [9]

Figura 3 - Robô inseto Genghis I controlado por comportamento.

(BROOKS, 1999) [16]

Figura 4 - Robôs R2e baseados em comportamento para coleta de lixo tóxico. (GOLDBERG, 2001) [45]

Figura 5 - Robôs AIBO da empresa SONY. Simula o comportamento de um cachorro real. (STONE, 2007) [46]

Figura 6 - Campo de competição de futebol de robôs. (STONE, 2007) [46]

Figura 7 - Robôs ISX utilizados para experimentos com controle

baseado em comportamento. (MATARIC, 1997) [47]

Figura 8 - Robô MOVEMASTER a) Robô Fixo b) Juntas associadas

(MURPHY, 2000) [26]

Figura 9 - Robô Soujorner - Robô para exploração de ambientes

dinâmicos e desconhecidos (MURPHY, 2000) [26].

Figura 10 - Arquitetura Horizontal de Controle. Modelo SMPA

(Sense, Model, Plan, Act)

Figura 11 - Arquitetura Vertical de Controle.

Figura 12 - Arquitetura Subsumption.

Figura 13 - Robôs reativos. a) Expressa medo. b) Expressa agressividade.

Figura 14 - Robôs reativos. a) Expressa amor. b) Expressa curiosidade.

Figura 15 - Comportamentos complexos gerados a partir da interação entre comportamentos simples.

Figura 16 - Diagrama representativo da arquitetura Motor Schema.

Figura 17 - Campos potenciais mais comuns. a) Uniforme b) Perpendicular c) Atrativo d) Repulsivo e) Tangencial 
Figura 19 - Campos repulsivo 3D para navegação submarina.

(MURPHY 2000) [26] 46

Figura 20 - Campo potencial Move-to-goal. 47

Figura 21 - Campo potencial Avoid-static-obstacle. 48

Figura 22 - Campos potenciais Move-to-goal e Avoid-static-obstacle

sobrepostos.

Figura 23 - Trajetória de um robô no ambiente com campos potenciais

Move-to-goal e Avoid-static-obstacle sobrepostos. 50

Figura 24 - Ambiente de simulação do STAGE. 52

Figura 25 - Capacidade de simulação do Stage. (2000 robôs Pioneer 2-DX). 52

Figura 26 - Robô Pioneer 2-DX real, simulado simplificado e simulado de forma completa.

Figura 27 - Ambiente de simulação Gazebo. 54

Figura 28 - Sensor LASER identificando um robô predador. 56

Figura 29 - Sensor SONAR identificando obstáculo. 57

Figura 30 - Sensor BLOBFINDER identificando um robô predador

em vermelho, objeto desejado em azul, e local de destino em amarelo. $\quad 58$

Figura 31 - GRIPPER com seus dois sensores de presença capturando um objeto desejado. $\quad 59$

Figura 32 - BUMPERS Cinco bumpers dispostos ao redor do robô. 59

Figura 33 - Sensores ultrassônicos. [17] 61

Figura 34 - Sensor ultrassonico utilizado. Modelo SRF10. 61

Figura 35 - Sensor infravermelho utilizado. QRD1114

FairChild Semiconductors. [19] 62

Figura 36 - Ambiente de simulação. $\quad 64$

Figura 37 - Topologia dos esquemas motores e perceptivos do robô coleta. 69

Figura 38 - Topologia dos esquemas motores e perceptivos do robô predador. 69

Figura 39 - Trajetória executada pelo robô de coleta apenas com

$\begin{array}{ll}\text { o comportamento EXPLORAR ativo. } & 70\end{array}$

Figura 40 - Trajetória de desvio do robô predador feita pelo robô de coleta. 72

Figura 41 - Trajetória dos esquemas motores AQUISITAR, PEGAR e a

ativação do ENTREGAR.

Figura 42 - Trajetória dos esquemas motores ENTREGAR, SOLTAR e a 
ativação do EXPLORAR.

Figura 43 - Topologia do robô verde e do robô vermelho programados com controle baseado em comportamento.

Figura 44 - Trajetória dos robôs controlados por comportamento.

Robô verde desvia e escapa do robô vermelho.

Figura 45 - Trajetória dos robôs verde e vermelho (baseados em

comportamento) em rota de colisão em um corredor estreito. 78

Figura 46 - Trajetória não linear do robô verde dentro do corredor. $\quad 80$

Figura 47 - Trajetória de desvio dos robôs programados com método clássico. 81

Figura 48 - Colisão entre os robôs programados com método clássico. 82

Figura 49 - Topologia do robô predador e do robô presa programados

com controle baseado em comportamento. $\quad 87$

Figura 50 - Robôs predador e presa no ambiente. $\quad 88$

Figura 51 - Trajetória dos robôs predador e presa navegando pelo ambiente. 89

Figura 52 - Trajetória dos robôs presa desviando do robô predador. 90

Figura 53 - Trajetória de fuga do robô presa. $\quad 91$

Figura 54 - Robô predador atinge robô presa. $\quad 92$

Figura 55 - Robô predador e respectivos sensores de ultrassom. 94

Figura 56 - Sensores infravermelhos localizados nas extremidades

da base do robô. $\quad 95$

Figura 57 - Robô predador, em verde, e robô presa, em azul, na arena. 96

Figura 58 - Topologia dos robôs reais predador e presa programados com controle baseado em comportamento. 97

Figura 59 - Robô predador executando esquema motor EXPLORAR. 98

Figura 60 - Robô predador desviando da faixa de perigo. 99

Figura 61 - Manobra de desvio do robô presa. 100

Figura 62 - Manobra de fuga do robô presa. 101

Figura 63 - Início da trajetória de captura da presa. 102

Figura 64 - Fim da trajetória de captura da presa. 103 